\title{
HERBICIDAS INIBIDORES DA EPSPS: REVISÃO DE LITERATURA
}

\author{
Nelson D. Kruse' ${ }^{1}$, Michelangelo M. Trezzi ${ }^{2}$ e Ribas A. Vidal ${ }^{3}$ \\ ${ }^{1}$ Engenheiro Agrônomo, MSc, Professor da UFSM-RS. Faculdade de Agronomia da Universidade Federal do Rio Grande do Sul. Caixa Postal 776 \\ Porto Alegre, RS 91501-970 \\ 2 Engenheiro Agrônomo, MSc, Professor do CEFET-PR. Faculdade de Agronomia da Universidade Federal do Rio Grande do Sul. \\ ${ }^{3}$ Engenheiro Agrônomo, PhD, Professor. Faculdade de Agronomia da Universidade Federal do Rio Grande do Sul. vidal@if1.if.ufrgs.br
}

\begin{abstract}
RESUMO
Os herbicidas inibidores da enzima EPSPs, glyphosate e sulfosate, estão entre os produtos mais comercializados no Brasil e no mundo. Os objetivos dessa revisão de literatura são sintetizar informações quanto ao espectro de ação, características físico-químicas, princípios da absorção, translocação, metabolização, mecanismo de ação, comportamento ambiental e a resistência de plantas aos herbicidas inibidores de EPSPs. Com essa revisão, espera-se fornecer subsídios para que a comunidade agrícola possa utilizar esses compostos de forma mais racional, eficaz e econômica.
\end{abstract}

Palavras-chave: absorção, translocação, metabolização, mecanismo de ação, resistência de plantas daninhas, resistência de culturas.

\section{ABSTRACT \\ Herbicides inhibitors of EPSPs: literature review}

The herbicides inhibitors of the enzyme EPSPs, glyphosate and sulfosate, are among the most used compounds in Brazil and in the world. The objectives of this review are to synthesize the information about the weeds controlled, physic-chemical characteristics, fundamentals of absorption, translocation, decomposition, mechanism of action, environmental performance, and plant resistance to the EPSPs inhibitors. With this review, we want to provide to the agricultural community information to obtain a more rational, efficient and economical performance of these compounds.

Key words: herbicides, EPSPs inhibitors, absorption, translocation, decomposition, mechanism of action, weed resistance, crop resistance.

\section{INTRODUÇÃO}

Os herbicidas inibidores da enzima enol-piruvil shiquimato fosfato sintase (EPSPs) tem como ingrediente ativo o herbicida $\mathrm{N}$-(fosfonometil) glicina (glyphosate). Atualmente, no Brasil, glyphosate é formulado como sal isopropilamina (IPA), sal monoamônio (MAM) ou sal trimetilsulfônio (TMS), sendo que o ingrediente ativo dessa última formulação também é denominado de sulfosate (Ahrens, 1994; Franzet al., 1997).

A molécula glyphosate foi inventada em 1950, pela indústria Cilag/Ciba, na Suíça, num processo de seleção de compostos quelatizantes para tintas. Na década de 60 , cientistas da Stauffer também descobriram outras propriedades quelatizantes de glyphosate. Somente no início dos anos 70, cientistas da Monsanto descobriram as propriedades 
herbicidas de glyphosate. A primeira marca comercial a base de glyphosate começou a ser vendida em 1974, sendo que duas décadas depois havia mais de 90 herbicidas com esse ingrediente ativo. Os inibidores de EPSPs perfazem $12 \%$ das vendas globais de herbicidas, sendo distribuídos em 119 países e somando mais de 150 marcas comerciais (Franz et al., 1997; Heap, 1997).

A introdução de inibidores de EPSPs no mercado brasileiro, no final dos anos 70, impulsionou o manejo químico de plantas daninhas no sistema de semeadura direta, pois possibilitou a dessecação de um grande número de espécies daninhas, especialmente daquelas de ciclo anual em estádios de desenvolvimento mais avançados e de espécies perenes (Velloso \& Souza, 1993).

Glyphosate é um herbicida sistêmico de ação total, facilmente translocável, motivo pelo qual provoca a morte do sistema radicular e de estruturas reprodutivas de plantas perenes, como rizomas, bulbos e tubérculos. Permite a semeadura de culturas imediatamente após a aplicação, em função de sua rápida e forte adsorção ao solo. A decomposição microbiana é rápida e as perdas por volatilização são insignificantes.

As diferentes formulações dos inibidores de EPSPs apresentam baixa toxicidade para mamíferos, pássaros, peixes, insetos e a maioria das bactérias. Isto acontece porque estes organismos não possuem a enzima EPSPs e obtêm aminoácidos aromáticos de suas dietas (Ahrens, 1994; Franz et al., 1997; Rodrigues \& Almeida, 1998)

A sensibilidade das plantas cultivadas a este herbicida tem limitado seu uso em pós-emergência de culturas. Atualmente, o desenvolvimento de culturas resistentes aos inibidores de EPSPs amplia o potencial de utilização destes herbicidas e pode facilitar o manejo de plantas daninhas nestas culturas.

Esta revisão de literatura objetiva caracterizar os herbicidas inibidores da enzima EPSPs, considerando principalmente os mecanismos de absorção, translocação, metabolização, o modo de ação destes produtos e a resistência de plantas a esses herbicidas.

\section{Aspectos gerais}

Os inibidores de EPSPs são herbicidas de ação total, de amplo espectro, que controlam plantas mono e dicotiledôneas anuais e perenes. São amplamente utilizados em operações de manejo (dessecação) em pós-emergência de plantas daninhas e antes da semeadura ou emergência das culturas. Como estes compostos são adsorvidos fortemente ao solo, não possuem ação residual (Ahrens, 1994; Franz et al., 1997; Rodrigues \& Almeida, 1998).

Estes herbicidas não penetram em caules lenhosos, sem epiderme verde, de árvores e videiras, apresentando segurança para uso em pomares e áreas de reflorestamento, des- de que as folhagens não sejam atingidas. Podem ser utilizados, também, para eliminar soqueiras de cana-de-açúcar e pastagens, por ocasião da renovação, em aplicações dirigidas nas entrelinhas de culturas. Em alguns países, há registro para o uso de inibidores de EPSPs para eliminar plantas daninhas em ambientes aquáticos (Ahrens, 1994; Franz et al., 1997; Vidal, 1997; Rodrigues \& Almeida, 1998).

O coeficiente de partição octanol/água (log Kow) de glyphosate é extremamente baixo $(-4,1)$, indicando baixíssima afinidade por lipídios e elevada solubilidade em água. Glyphosate apresenta quatro constantes de dissociação (pKa's) com valores de 0,3 ,2,2, 5,5 e 10,3, adquirindo características de cátion, neutro, monoânion, diânion e triânion. Sob pHs fisiológicos, nos vegetais o glyphosate se comporta como monoânion ou diânion. Em função das diferentes cargas que a molécula pode assumir, a variação de $\mathrm{pH}$ do solo tem pouco efeito sobre a adsorção de glyphosate (Ahrens, 1994; Franzet al., 1997).

\section{Absorção e translocação}

Os herbicidas inibidores de EPSPs são absorvidos principalmente pela parte aérea da planta, já que, quando aplicados ao solo, são fortemente adsorvidos. A camada cuticular sobre a superfície das folhas é considerada a maior barreira para a absorção de herbicidas. A estrutura molecular do herbicida, a utilização de adjuvantes e as condições climáticas são fatores importantes nos processos de absorção e translocação.

Glyphosate é absorvido moderadamente pela cutícula, necessitando em média de 6 horas sem chuvas após a aplicação para haver controle adequado de plantas sensíveis. É possível que a absorção relativamente lenta de glyphosate ocorra devido ao valor muito baixo de log Kow (próximo a -4), em comparação com outros herbicidas, o que lhe confere baixa lipofilicidade. Assim, novas formulações apresentam surfactantes que conferem maior lipofilicidade à solução aspergida, facilitando a absorção foliar dos inibidores de EPSPs (Boerboom \& Wyse, 1988; Mac Isaac et al., 1991; Franz et al., 1997; Rodrigues \& Almeida, 1998).

O processo de difusão é considerado o mais provável para o transporte de glyphosate através da cutícula e o gradiente de concentração entre a região de deposição do produto e o interior da planta deve influenciar sua taxa de absorção. A elevação da concentração de glyphosate na superfície, desta forma, aumenta a sua absorção. Isto explica porque aspersões de glyphosate com baixo volume de calda aumentam a absorção e a eficácia do produto (Buhler \& Burnside, 1983; Liu et al., 1996; Franz et al., 1997).

O aumento da tensão de umidade no solo, que ocorre com o secamento do solo, pode reduzir fortemente a eficácia de glyphosate sobre várias plantas daninhas, em função da redução de sua absorção pelas plantas (Ahmadi et al., 1980; 
MC Whorter et al., 1980). Em geral, a baixa umidade relativa do ar induz à formação de maior quantidade de cera epicuticular na superfície das folhas, reduzindo a absorção de inibidores de EPSPs (Sherrick et al., 1986). Contudo, a composição e integridade da cutícula são mais importantes no impedimento à absorção de glyphosate do que a espessura da cutícula (Westwood et al., 1997).

O uso de surfactantes aumenta a eficácia de glyphosate, pelo aumento da retenção de gotas nas folhas e da absorção foliar. Estes produtos aumentam a hidratação da cutícula, incrementando a difusão de glyphosate através da mesma (Sherrick et al., 1986; Gaskin \& Holloway, 1992; de Ruitner \& Meinen, 1998).

A penetração de glyphosate nas células é mediada por proteínas transportadoras de fosfato, presentes na plasmalema (Mervosh \& Balke, 1991). Glyphosate é translocado nas plantas até os tecidos de demanda, através do floema, onde é distribuído simplasticamente, embora também ocorra movimento apoplástico. Este composto aparentemente tem dificuldade de penetrar no floema, contudo, uma vez ali localizado é altamente móvel, aproximando-se do limite teórico de mobilidade no floema (Gougler \& Geiger, 1984; Franz et al., 1997).

Logo após a aplicação, os inibidores de EPSPs reduzem a importação de assimilados por folhas jovens em desenvolvimento. Mais tarde, a fotossíntese é reduzida e a acumulação de amido é interrompida, mas a exportação de assimilados e de glyphosate continua, até ser limitada pela baixa disponibilidade de amido, durante a noite. Várias teorias explicam a auto-limitação da translocação de glyphosate: (a) inibição da fixação de $\mathrm{CO}_{2}$; (b) interrupção da síntese de amido; (c) limitação do uso de amido armazenado; (c) dano à integridade dos elementos crivados; (e) limitação do fluxo de importação e descarregamento de sacarose (Geiger \& Bestman, 1990).

A redução da umidade do solo decresce a eficiência de translocação de glyphosate em capim-arroz (Echinochloa cruss-galli) e capim massambará (Sorghum halepense) (Ahmadi et al., 1980; MC Whorter et al., 1980). Maior intensidade luminosa nos sete dias subseqüentes à aplicação favorecem a translocação de ${ }^{14} \mathrm{C}$-glyphosate até as partes da planta não tratadas (Schultz \& Burnside, 1980).

Embora a adição de surfactante geralmente resulte em elevação da absorção de glyphosate, pode reduzir a translocação do produto. Isto depende da concentração de surfactante utilizada. A adição de $1 \% \mathrm{p} / \mathrm{v}$ de dois tipos de surfactantes diferentes reduziu a translocação de glyphosate, em comparação ao herbicida sem adição do surfactante. A redução da translocação esteve associada à injúria nos tecidos adjacentes ao local de aplicação. Contudo, a adição na concentração de apenas $0,1 \%$ p/v maximizou a translocação (Sherrick et al., 1986).

Resultados conflitantes são encontrados em relação ao efeito da concentração de glyphosate sobre sua translocação. Elevada concentração de glyphosate aplicado sobre plantas de Cirsium arvense resultou em redução de sua translocação, em função da elevada fitotoxicidade (Boerboom \& Wyse, 1988). Já em plantas de Populus tremuloides, houve aumento da translocação de glyphosate com aumento da sua concentração, independentemente do tamanho e do número de gotas da aplicação (Liu et al., 1996).

\section{Metabolização}

As espécies vegetais possuem diferentes graus de metabolização dos inibidores de EPSPs. Algumas espécies, como Agropyron repens e Equisetum arvense têm demonstrado metabolização significativa de glyphosate até aminometil fosfonato (AMPA) (Coupland, 1984; Marshall et al., 1987; Dyer, 1994). No trabalho com Agropyron repens, a elevação da temperatura de $10 / 6^{\circ} \mathrm{C}$ para $26 / 16^{\circ} \mathrm{C}$ (noite/dia) resultou em maior metabolização de glyphosate e de maior produção de ${ }^{14} \mathrm{CO}_{2}$ (Coupland, 1984). No caso de Equisetum arvense, a degradação atingiu tal magnitude que os autores sugeriram que ela foi parcialmente responsável pelo baixo desempenho de glyphosate sobre esta espécie (Marshall et al., 1987). No entanto, críticas foram feitas ao fato de que estes estudos não foram feitos com plantas esterilizadas, o que deixa dúvidas se os metabólitos produzidos são originários de plantas ou de contaminação microbiana (Dyer, 1994).

Experimentos avaliando a metabolização dos inibidores de EPSPs, utilizando culturas de suspensão de células esterilizadas de trigo, soja, feijão e milho, mostraram taxas variáveis de metabolização do herbicida. O conteúdo de AMPA em soja foi de $50 \%$, enquanto em trigo e em milho foi menor do que $5 \%$ (Komoba et al., 1992, citado por Franz et al., 1997).

As bactérias do solo degradam glyphosate, produzindo o aminoácido glicina e AMPA como intermediários. A formação de glicina ocorre após a quebra da ligação C-P de glyphosate, dando origem a um precursor chamado sarcosina, enquanto AMPA é gerado pela clivagem da ligação carboximetil C-N (Dyer, 1994; Padgette et al., 1996).

\section{Mecanismo de ação}

A enzima 5-enolpiruvoilshiquimato 3 -fosfato sintase (EPSPs, E.C. 2.5.1.19) está presente na rota de síntese dos aminoácidos aromáticos fenilalanina, tirosina e triptofano. Sua inibição pelo herbicida glyphosate e seus sais, bloqueia a síntese daqueles aminoácidos nas plantas, acumulando um composto intermediário chamado shiquimato (Vidal, 1997).

A enzima EPSPs é codificada no núcleo e desempenha sua ação catalítica no cloroplasto, sendo fortemente inibida pelo glyphosate em todas as plantas, fungos e a maioria das bactérias analisadas. EPSPs está presente em todos esses organismos, mas não ocorre em animais, o que explica a essencialidade dos aminoácidos derivados da rota (exceção 
para tirosina que pode ser produzida a partir de fenilalanina), e a baixa toxicidade do glyphosate para mamíferos (Franz et al., 1997).

EPSPs cataliza a reação do shiquimato-3-fosfato (S3P) e fosfoenolpiruvato (PEP) para produzir 5enolpiruvilshiquimato-3-fosfato (EPSP) e fosfato inorgânico (Pi) (Figura 1). Essa reação ocorre em duas etapas, onde inicialmente a enzima EPSPs se liga ao S3P, formando o complexo EPSPs-S3P, e posteriormente o PEP se encaixa nesse complexo, permitindo o prosseguimento da reação produzindo EPSP. Glyphosate não se liga à enzima livre, mas ao complexo EPSPs-S3P, impedindo a ligação de PEP, formando o complexo inativo EPSPS-S3P-glyphosate (Devine et al., 1993; Herrmann, 1995; Padgette et al., 1995). De fato, glyphosate liga-se ao complexo EPSPS-S3P 115 vezes mais firmemente do que PEP e apresenta dissociação 2300 vezes mais lenta do que PEP (Franz et al., 1997).
Nas plantas, a EPSPs é sintetizada no citoplasma e necessita estar ligada a um peptídeo de trânsito para dirigir-se ao cloroplasto, numa forma conhecida como pré-enzima (pEPSPs), conduzindo-se dessa forma à membrana do cloroplasto, sendo recebida por um receptor e liberado no lado interno da membrana na forma ativa da enzima. A ligação e inibição de glyphosate à enzima parece ocorrer também no citoplasma, podendo formar o complexo glyphosate-pEPSPs-S3P. A estabilidade estrutural desse complexo impede a necessária flexibilidade conformacional para o transporte através da membrana do cloroplasto (Devine et al., 1993; Franz et al., 1997).

A inibição da enzima EPSPs interfere no controle da entrada de carbono na rota do shiquimato, pelo aumento da atividade da enzima 3-deoxi-D-arabino-heptulosonato-7fostato sintase (DAHPS) (Enzima 1 na Figura 1), que cataliza a condensação de eritrose-4-fosfato com PEP, e é considerada a enzima reguladora da rota. Essa enzima requer um íon como<smiles>O=C(O)C1=CC(=O)[C@H](O)C(O)C1</smiles>

Ácido 3-dehidroshiquimico<smiles>C#CC1=C[C@@H](O)[C@H](O)C(O)C1</smiles>

Ácido shiquímico

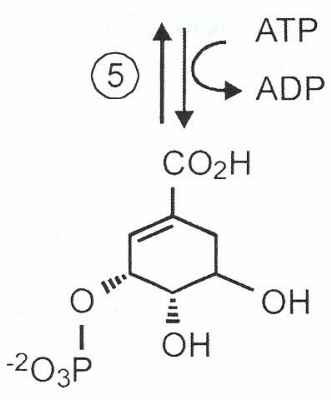

Shiquimato 3-fosfato<smiles>O=C1CC(O)(C(=O)O)CC(O)[C@H]1O</smiles>

3-dehidroshiquímico<smiles>O=C(O)C1CC(O)[C@@H](O)C(COP(=O)(O)c2ccccc2)O1</smiles>

Deóxiarabino heptulosonato 
cofator, podendo ser ou $\mathrm{Mn}^{2+}$ ou $\mathrm{Co}^{2+}$, resultando assim em duas isoenzimas. $\mathrm{O}$ aumento da atividade da DAHPS dependente de $\mathrm{Mn}^{2+}$, isoforma presente no cloroplasto, é aparentemente devido aos baixos níveis de arogenato, composto posterior ao corismato na rota do shiquimato, e inibidor alostérico da DAHPS. Com a redução da inibição por arogenato, DAHPS continua atuando, o que provoca acúmulo de altos níveis de shiquimato, já que a rota está interrompida pela inibição da EPSPS (Figura 1) (Franz et al., 1997).

A quantidade de shiquimato que é acumulado pela desregulação da rota, representa um forte dreno de carbono no ciclo de Calvin, pelo desvio de eritrose-4-fosfato, que seria empregado na regeneração de ribulose bifosfato do mesmo ciclo. Isso representa um efeito secundário importante da inibição do glyphosate, que reduz drasticamente a produção fotossintética de sacarose, o que limita a própria translocação do glyphosate, ao redor do segundo dia após a absorção do herbicida (Devine et al., 1993; Franz et al., 1997; Geiger \& Bestman, 1990).

Esta rota metabólica é fonte dos aminoácidos citados para a síntese proteica, mas também é precursora de vários outros compostos aromáticos importantes como vitaminas ( $\mathrm{K}$ e E), hormônios (auxina, etileno), alcalóides, lignina, antocianina e vários outros produtos secundários. Estima-se que $35 \%$ ou mais da massa seca das plantas é representado por derivados da via do shiquimato, ou ainda que $20 \%$ do carbono fixado pela fotossíntese segue por essa rota metabólica (Devine et al., 1993; Franz et al., 1997).

\section{Comportamento no solo}

Glyphosate é altamente adsorvido aos colóides do solo, não ficando disponível para absorção pelas plantas. A adsorção ocorre rapidamente, dentro de poucas horas após o tratamento, havendo pouca influência do $\mathrm{pH}$ na mesma. Há evidências de que glyphosate liga-se ao solo através da parte fosfônica de sua molécula com cátions polivalentes adsorvidos nas argilas e matéria orgânica. A adsorção parece estar relacionada ao conteúdo de argila e à capacidade de troca de cátions do solo. A presença de cátions aumenta a adsorção do glyphosate na seguinte ordem: $\mathrm{Na}^{+}<\mathrm{Ca}^{2+}<\mathrm{Mg}^{2+}<\mathrm{Cu}^{2+}<$ $\mathrm{Fe}^{3+}$ (Morillo et al., 1997; Span \& Hargreaves, 1994).

Com relação à adsorção de glyphosate à matéria orgânica do solo, parece que os íons metálicos ligados à matéria orgânica é que são responsáveis pela ligação do glyphosate à esta fração do solo. Glyphosate pode ligar-se a substâncias húmicas através da formação de pontes de hidrogênio. De fato, a extensão com que glyphosate se liga às substâncias húmicas do solo varia bastante, em função do caráter alifático ou aromático dessas substâncias e à dimensão de suas moléculas. Quanto maior o caráter alifático e maior o tamanho da molécula, mais fortemente o glyphosate estará ligado, podendo até equivaler-se à extensão com que se liga à fração mineral do solo (Piccolo et.al., 1996). Apesar da alta solubilidade em água dos sais de glyphosate, a elevada adsorção confere aos inibidores de EPSPs a característica de baixa lixiviação no perfil do solo (Franz et al., 1997).

A degradação de glyphosate pela flora microbiana é a rota predominante de sua metabolização no ambiente, estando diretamente correlacionada com a atividade microbiana e sendo bastante variável entre diferentes solos. Ocorre tanto em condições aeróbicas quanto anaeróbicas, iniciando rapidamente e seguindo-se mais lentamente por um período prolongado. $\mathrm{O}$ pH e o conteúdo de matéria orgânica exercem pouca influência na degradação microbiana, sendo mais influenciada por fatores que possam afetar sua disponibilidade no solo, como a presença de fosfatos (aumenta) e cátions (diminui). A degradação no solo indica a formação de amônia, fosfato, $\mathrm{CO}_{2}$ e glioxilato, que, através do ciclo do ácido cítrico, é transformado a $\mathrm{CO}_{2}$ e outros produtos naturais. Considerando-se o grande espectro de microorganismos no solo, poucos microrganismos são capazes de degradar glyphosate. Entre eles incluem-se bactérias do gênero Arthrobacter e Pseudomonas, além de algumas espécies da família Rhizobiaceae (Franz et al., 1997).

\section{Resistência de plantas daninhas aos inibidores de EPSPs}

Resistência é a habilidade herdável de alguns biótipos de plantas, dentro de uma população, em sobreviver a herbicida aplicado em doses que controlam a espécie. Atualmente estão documentados três espécies com biótipos resistentes aos inibidores de EPSPs (Bradshaw et al., 1997; Gruys et al., 1999; Lorraine-Colwill et al., 2000; Zelaya \& Owen, 2000).

$\mathrm{Na}$ Austrália, um biótipo de Lolium rigidum desenvolveu resistência a glyphosate, sendo constatada pela primeira vez, em 1996. Glyphosate havia sido usado como dessecante na área pelo menos 10 vezes em 15 anos, o que resultou na seleção da resistência. Estudos confirmaram ser o biótipo seis vezes mais resistente que a população normal suscetível. Não está claro qual é o mecanismo responsável pela resistência, mas supõe-se que seja algum aspecto relacionado à maior estabilidade de RNAm, o que possibilita maior produção da enzima EPSPs (Gruys et al., 1999). A resistência de Lolium rigidum ao glyphosate se deve à expressão de um gene nuclear e dominante (Lorraine-Colwill et al., 2000).

Na Malásia, documentou-se que biótipos de Eleusine indica desenvolveram resistência aos inibidores de EPSPs. Em Eleusine indica, o mecanismo da resistência é a alteração no gene de EPSPs que reduz a sensibilidade dessa enzima ao herbicida glyphosate em cinco vezes, no biótipo resistente, comparado com o suscetível (Dill et al., 2000).

Nos Estados Unidos, encontraram-se biótipos de Amaranthus rudis resistentes ao glyphosate, sendo constatados pela primeira vez em 1998. Resultados preliminares tam- 
bém indicam que esses biótipos apresentam baixa sensibilidade da enzima EPSPs aos inibidores da mesma (Zelaya \& Owen, 2000).

Esses biótipos resistentes aos inibidores de EPSPs indicam que os herbicidas com esse mecanismo de ação devem ser utilizados de forma criteriosa, utilizando-se rotações de herbicidas de mecanismos de ação diferentes, além de outras práticas de manejo de plantas daninhas, para minimizar a oportunidade de ocorrência do problema em nosso país.

\section{Resistência de culturas aos inibidores de EPSPs}

Resistência de culturas aos herbicidas segue o conceito expresso no item anterior, com a diferença que não se tratam de biótipos que surgem naturalmente, mas de um determinado genótipo no qual a resistência é incorporada. Essa resistência pode ser oriunda de seleções naturais dentro da própria cultura (seleções somaclonais em cultura de tecidos) ou por transformação de plantas, gerando culturas transgênicas.

Essa revisão restringir-se-á a relatar a tecnologia corrente de emprego de resistência ao glyphosate em soja através do gene que confere insensibilidade à enzima EPSPS. Esse gene é denominado CP4 e provém de bactéria de solo do gênero Agrobacterium, identificada a partir da seleção entre micróbios que decompõem glyphosate. A EPSPs proveniente do gene CP4 tem elevada afinidade para PEP, enquanto é resistente aos inibidores de EPSPs. Para ser incorporado em linhagens de soja, o gene foi fundido a uma seqüência de genes derivada da EPSPs de petúnia (promotor) e introduzido pelo método de Bio-galística. A linhagem foi posteriormente cruzada com linhagens elite (de alto desempenho agronômico) produzindo segregação de 3:1 na F1, indicando o caráter dominante do gene. A produtividade, morfologia e constituição das cultivares de soja com a resistência incorporada permaneceu igual às linhagens susceptíveis correspondentes. Linhagens de soja com esse gene tratadas com glyphosate, nas doses comerciais, não apresentaram sintomas de fitotoxicidade ou redução da produtividade e qualidade do produto, viabilizando seu uso comercial (Padgette et al., 1995; Racchi et al., 1995; Scott et al., 1998). Várias outras culturas tem recebido atenção no sentido de introdução desse gene que confere insensibilidade de EPSPs ao glyphosate, incluindo milho, arroz, fumo e tomate.

Recentemente, tem sido introduzido o gene GOX, que confere capacidade de metabolização do glyphosate. Esse gene é responsável pela síntese da enzima C-P liase, que decompõe glyphosate, produzindo AMPA e glioxilato. O uso dessa técnica é preconizado para espécies com menor habilidade de metabolizar glyphosate do que a soja, para reduzir os níveis residuais de glyphosate que permaneceriam no produto comercial da cultura. A cultura que possuir os genes CP4 e GOX, terá EPSPs insensível ao glyphosate e será capaz de metabolizá-lo, garantindo o produto colhido livre de resíduos do herbicida (Duke, 1996).
No Brasil, a liberação de semeadura de culturas resistentes aos inibidores de EPSPs depende da autorização da Comissão Técnica Nacional de Biossegurança, entre outros órgãos governamentais, devido ao fato da resistência ter sido obtida pelas técnicas de engenharia genético-molecular.

\section{CONSIDERAÇÕES FINAIS}

As informações contidas nessa revisão estão organizadas sintetizar o conhecimento atual sobre o comportamento dos inibidores de EPSPs no ambiente e nas plantas. Se forem bem utilizados pela comunidade agrícola, poderão contribuir para que esse herbicida seja utilizado de forma mais racional, mais eficiente e, conseqüentemente, de maneira mais econômica e segura.

\section{LITERATURA CITADA}

AHMADI, M.S.; HADERLIE, L.C.; WICKS, G.A. Effect of growth stage and water stress on barnyardgrass (Echinochloa crus-galli) control and on glyphosate absorption and translocation. Weed Science, Champaign, v. 28, n. 3, p. 277-282, 1980.

AHRENS, W. H (ed.) Herbicide handbook. 7. Ed. Champaign: WSSA, 1994.352 p.

BOERBOOM, C.M; WYSE, D.L. Influence of glyphosate concentration on glyphosate absorption and translocation in canada thistle (Cirsium arvense). Weed Science, Champaign, v. 36, n. 1, p. 291-295, 1988.

BRADSHAW, L.D.; PADGETTE, S.R.; KIMBALL, S.L.; WELLS, B.H. Perspectives on glyphosate resistance. Weed Technology, Champaign, v. 11, n. 1, p. 189-198, 1997.

BUHLER, D.D.; BURNSIDE, D.C. Effect of spray components of glyphosate toxicity to annual grasses. Weed Science, Champaign, v. 31, n. 1, p. 124-130, 1983.

COUPLAND, D. The effect of temperature on the activity and metabolism of glyphosate applied to rhizome fragments of Elimus repens. Pesticide Science, Oxford, v. 15, n. 2, p. 226-234, 1984.

de RUITNER, H.; MEINEN, E. Influence of water stress and surfactant on the efficacy, absorption, and translocation of glyphosate. Weed Science, Lawrence, v. 46, n. 3, p. 289-296, 1998.

DEVINE, M.; DUKE, S.O.; FEDTKE, C. Physiology of herbicide action. Englewood Cliffs, NJ: PTR Prentice Hall, 1993, 441p. Cap. 13: Inhibition of amino acid biosynthesis. 
Herbicidas inibidores da EPSPs

DYER, W. E. Resistance to glyphosate. In: POWLES, S. \& HOLTUM, J. A. M. (eds.) Herbicide resistance in plants: biology and biochemistry. Boca Raton: CRC Press, 1994. p. 221-241.

DILL, G.; BAERSON, S.; CASAGRANDE, L. et al. Characterization of glyphosate resistant Eleusine indica biotypes from Malaysia. In: INTERNATIONAL WEED SCIENCE CONGRESS, 3, 2000, Foz do Iguaçú, PR, Brazil. Abstracts... Corvallis: IWSS, 2000. p.150.

DUKE, S. O. (ed.) Herbicide-resistant crops: agricultural, environmental, economic, regulatory, and technical aspects. Boca Ratoon: Lewis, 1996. 420 p.

FRANZ, J.E.; MAO, M.K.; SIKORSKI, J.A. Glyphosate: a unique global herbicide. Washington, DC: ACS monograph, 1997.653p.

GASKIN, R.E.; HOLLOWAY, P.J. Some physicochemical factors influencing foliar uptake enhancement of glyphosate-mono (isopropylammonium) by polyoxyethylene surfactants. Pesticide Science, Oxford, v. 34, n. 3, p. 198-206, 1992.

GEIGER, R.D.; BESTMAN, H.D. Self-limitation of herbicide mobility by phytotoxic action. Weed Science, Champaign, v. 38, n. 3, p. 324-329, 1990

GOUGLER, J.A.; GEIGER, D.R. Carbon partitioning and herbicide transport in glyphosate-treated sugarbeet (Beta vulgaris). Weed Science, Champaign, v. 32, n. 5, p. 546551,1984

GRUYS, K.J.; BIEST-TAYLOR, N.A.; FENG, P.C.C. et al. Resistance to glyphosate in annual ryegrass (Lolium rigidum) II. Biochemical and molecular analyses. In: MEETING OF THE WEED SCIENCE SOCIETY OF AMERICA, 39, 1999, San Diego, CA, EUA. Abstracts... Lawrence: WSSA, 1999. p.82.

HEAP, I.M. The occurrence of herbicide resistant weeds worldwide. Pesticide Science, Londres, v. 51, n. 2, p. 235-243, 1997.

HERRMANN, K.M. The shikimate pathway: early steps in the biosynthesis of aromatic compounds. The Plant Cell, Rockville, v.7, n.7, p 907-919, 1995.

LIU, S.H.; CAMPBELL, R.A; STUDENS, J.A. et al. Absorption and translocation of glyphosate in aspen (Populus tremuloides) as influenced by droplet size, droplet number and herbicide concentration. Weed Science, Champaign, v. 44, n. 3, p. 482-488, 1996.

LORRAINE-COLWILL, D. F.; PRESTON, C.; POWLES, S. B. et al. Genetic inheritance of glyphosate resistance in an Australian population of Lolium rigidum. In: INTERNATIONAL WEED SCIENCE CONGRESS, 3, 2000, Foz do Iguaçú, PR, Brazil. Abstracts... Corvallis: IWSS, 2000. p.148.
MAC ISAAC, S.A.; PAUL, R.N.; DEVINE, M. A scanning electron microscope study of glyphosate deposits in relation to foliar uptake. Pesticide Science, Oxford, v. 31, n. 1,p. 53-64, 1991.

MARSHALL, G.; KIRKWOOD, R.C.; MARTIN, D.J. Studies on the mode of action of asulam, aminotriazole and glyphosate in Equisetum arvense L. (field horsetail). II. The metabolism of $\left[{ }^{14} \mathrm{C}\right]$ asulam, $\left[{ }^{14} \mathrm{C}\right]$ aminotriazole and $\left[{ }^{14} \mathrm{C}\right]$ glyphosate. Pesticide Science, Oxford, v. 18, n. 1, p. 65-77, 1987.

MC WHORTER, C.G.; JORDAN, T.N.; WILLS, G.D. Translocation of $14 \mathrm{C}$-glyphosate in soybeans (Glycine max) and johnsongrass (Sorghum halepense). Weed Science, Champaign, v. 28, n. 1, p. 113-118, 1980.

MERVOSH, T.L.; BALKE, N.E. Effects of calcium, magnesium, and phosphate on glyphosate absorption by cultured plant cells. Weed Science, Champaign, v. 39, n. 3, p. 347$353,1991$.

MORILLO, E.; UNDABEYTIA, T.; MAQUEDA, C. Adsorption of glyphosate on clay mineral montmorilonita: effect of $\mathrm{Cu}$ (II) in solution and adsorbed on the mineral. Environmental Science Technology, v. 31, n. 12, p. 35883592, 1997.

PADGETTE, S.R.; KOLACZ, K.H.; DELANNAY, X. et al. Development, identification and characterization of a glyphosate-tolerant soybean line. Crop Science, Madison, n. 35, p. 1451-1461, 1995.

PADGETTE, S.R.; RE, D.B; BARRY, G.F. et al. New weed control opportunities: development of soybeans with a roundup ready gene. In: DUKE,S.O. (Ed.) Herbicide-resistant crops: agricultural, economic, environmetal, regulatory, and technological aspects. Boca Raton, FL.: CRC Press, 1996. p. 53-84.

PICCOLO, A.; CELANO, G.; CONTE, P. Adsorption of glyphosate by humic substances. Journal of Agricultural Food Chemistry, Washington, v. 44, p. 2442-2446, 1996.

RACCHI, M. L.; REBECCHI, M.; TEDESCO, G. et al. Glyphosate tolerance in maize (Zea mays L.). 2. Selection and characterization of a tolerant somaclone. Euphytica, Wageningen, v. 82, n. 1, p.165-173, 1995.

RODRIGUES, B.N.; ALMEIDA, F.S. Guia de herbicidas. 4. Ed. Londrina: IAPAR, 1998.648 p.

SCHULTZ, M.E.; BURNSIDE, O.C. Absorption, translocation, and metabolism of 2,4-D and glyphosate in hemp dogbane (Apocynum cannabinum), Weed Science, Champaign, v. 27, n. 1, p. 13-20, 1980.

SCOTT, R., SHAW; R. D.; BARRENTINE, W. L. Glyphosate tank mixtures with SAN 582 for burndown or 
postermergence applications in glyphosate-tolerant soybean (Glycine max). Weed Technology, Lawrence, v. 12, n. 1, p. 23-26, 1998.

SHERRICK, S.L.; HOLT, H.A.; HESS, F.D. Effects of adjuvants and environment during plant development on glyphosate absorption and translocation in field bindweed (Convolvulus arvensis). Weed Science, Champaign, v. 34, n. 5, p. 811-816, 1986.

SPAN, K.P.; HARGREAVES, P.A. The determination of glyphosate in soils with moderate to high clay content. Pesticide Science, Londres, v. 40, n. 1, p. 41-48, 1994.

VELLOSO, J.A.R.O.; SOUZA, R.O. Plantas daninhas no sistema de plantio direto. In: EMBRAPA/CEP FECOTRIGO/
FUNDAÇÃO ABC. Plantio direto no Brasil. Passo Fundo: Aldeia Norte, 1993. p. 61-75.

VIDAL, R. A. Herbicidas: mecanismos de ação e resistência de plantas. Porto Alegre: Ribas Vidal, 1997. 165 p.

WESTWOOD, J.H.; YERKES, C.N.; DE GENARO, F. et al. Absorption and translocation of glyphosate in tolerant and susceptible biotypes of field bindweed (Convolvulus arvensis). Weed Science, Lawrence, v. 45, n. 5, p. 658$663,1997$.

ZELAYA, I.A.; OWEN, M.D.K. Differential response of common waterhemp (Amaranhus rudis Sauer) to glyphosate in Iowa. In: MEETING OF THE WEED SCIENCE SOCIETY OF AMERICA, 39, 2000, Toronto, Canada. Abstracts... Lawrence: WSSA, 1999. p.62-63. 